Available online on 15.07.2017 at http://jddtonline.info
Journal Of Drug Delivery and Therapeutics
Open Access to Pharmaceutical and Medical Research
$\begin{gathered}\text { 2011-17, publisher and licensee JDDT, This is an Open Access article which permits unrestricted non- } \\ \text { commercial use, provided the original work is properly cited }\end{gathered}$

Open $\odot$ Access

Research Article

\title{
KNOWLEDGE, ATTITUDE AND PRACTICE OF HEALTHCARE PROFESSIONALS TOWARDS ADVERSE DRUG REACTION REPORTING AT INPATIENT WARDS OF TERTIARY HOSPITAL, ETHIOPIA
}

\author{
Adane Teshome Kefale ${ }^{{ }^{*}}$, Beza Dereje Tefera ${ }^{2}$, Tessema Tsehay Biru ${ }^{1}$ \\ ${ }^{1}$ Mizan-Tepi University, College of Health Sciences, Department of Pharmacy, Ethiopia \\ ${ }^{2}$ Arba Minch University, College of Health Sciences, Ethiopia
}

\section{ABSTRACT}

Background: Drugs have become one of an essential component of healthcare systems worldwide. However, there is a concern for their safety. Adverse drug reaction (ADR) is common during usual clinical practice and it is associated with increased morbidity, hospitalization and mortality.

Objective: To assess knowledge, attitude, and practice of healthcare professionals (HCPs) towards ADRs reporting at inpatient wards of Tikur Anbessa Specialized Hospital (TASH), Ethiopia.

Methods: Hospital based descriptive cross-sectional study was conducted among 280 HCPs at the inpatient wards of TASH. The data required for the present study was collected using self-administered structured questionnaire and samples were selected through both stratified and systematic random sampling methods, where the type of profession was used as a stratum. The collected data was analyzed using SPSS version 21.00 for the window.

Results: Of $280 \mathrm{HCPs}$ to whom the questionnaire initially administered, 213 respondents filled and returned the questionnaire, giving a response rate of $76.1 \%$, and were included in the analysis. The study revealed that $78.9 \%$ and $47.9 \%$ of HCPs have poor knowledge and negative attitude towards ADR reporting respectively. Among respondents, $38 \%$ of HCPs encountered patient with $\mathrm{ADR}, 90.2 \%$ of them reported the ADR they encountered, of them only $10.8 \%$ were reported to Ethiopian food, medicine, and healthcare administration and control authority, a regulatory body for receiving and monitoring ADR throughout the country.

Conclusion: HCPs in TASH had poor knowledge, attitude and practice towards ADRs reporting. The hospital should devise strategies to enhance detection and reporting of ADRs.

Key words: ADR reporting, pharmacovigilance, spontaneous reporting, TASH

Article Info: Received 27 June, 2017; Review Completed 11 July, 2017; Accepted 12 July, 2017; Available online 15 July, 2017

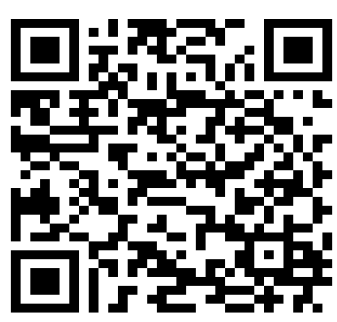

Cite this article as:

Kefale AT, Tefera BD, Biru TT, Knowledge, attitude and practice of healthcare professionals towards adverse drug reaction reporting at inpatient wards of tertiary hospital, Ethiopia, Journal of Drug Delivery and Therapeutics. 2017; 7(4):97-102

DOI: http://dx.doi.org/10.22270/jddt.v7i4.1483

*Address for Correspondence

Adane Teshome Kefale, Mizan-Tepi University, College of Health Sciences, Department of Pharmacy, Ethiopia; Email: adanet2011@gmail.com

\section{INTRODUCTION}

According to World Health Organization (WHO) definition, an ADR is any noxious and unintended effect of a drug, which occurs at doses used in humans for prophylaxis, diagnosis or cure of a disease ${ }^{1}$. Drugs play important role in day to day life of the human being to prevent and treat diseases as well as maintain overall wellbeing. Despite multiple benefit of drugs, they are not totally free from untoward effects. ${ }^{2,3}$
Post-marketing surveillance of drugs was used as an important tool in controlling drug safety for century; contributed a lot in the withdrawal of drugs from the market due to safety problem. Reporting ADRs is important for all types of drugs, whether newly released into market or renowned since ADR can be caused by any type of drug at any time. In spite of the necessity of continuous reporting and monitoring of ADRs to minimize its consequence, the practice is still poor 
particularity in developing countries because it requires adequate knowledge, skills, attitude and commitment by healthcare professionals and strict regulation and monitoring by drug regulatory bodies ${ }^{2,4}$.

Spontaneous reporting structure, a system whereby reports of ADRs are voluntarily submitted by HCPs and pharmaceutical manufacturers to national regulatory authority, is the most common way through which regulatory bodies collect information on ADRs ${ }^{5,6}$. Spontaneous reporting of ADRs remains the cornerstone of pharmacovigilance. However, the success of this activity is dependent on the reporting of all suspected ADRs by HCPs, which in turn affected by knowledge, attitude and commitments of HCPs. In western countries the incidence of ADRs is $2.4-6.5 \%$ of which only $6-10 \%$ of all ADRs being reported ${ }^{7,8}$.

A Number of factors might be attributed for underreporting of ADRs which include fearing to report, lack of time, different care priorities, uncertainty about the drug causing the ADR, difficulty in accessing reporting forms, lack of awareness of the requirements for reporting, unawareness about where to report and how to report, lack of feedback from regulatory authority and lack of understanding the purpose of spontaneous reporting systems ${ }^{9-12}$.

In Ethiopia voluntary ADR reporting has been effective since 2002 through the rigorous activities performed by the ADR monitoring division of the EFMHACA aimed to reduce ADR. A simple ADR reporting form was developed and it is made available in all health facilities across the country for identifying and reporting ADR. However, the number of reports received by the center still is small ${ }^{6,13}$.

\section{METHODS}

\section{Study Setting}

The study was conducted at inpatient wards of Tikur Anbessa Specialized Hospital (TASH), the largest referral hospital with over 700 beds, located in Addis Ababa, Ethiopia. The hospital provides services for people coming from different corners of the country. The hospital inpatient wards provide services with 14 physicians, 633 nurses and midwives, 76 pharmacists and 33 anesthetists who were hired to provide healthcare services. There was no well-established pharmacovigilance center in TASH.

\section{Study Design and Period}

A cross sectional study with two stage sampling, both stratified and systematic random sampling techniques, was conducted among HCPs. The data was collected from March 3-25, 2016 at inpatient wards of TASH. Respondents included in this study were those HCPs working at inpatient wards of TASH who were available during data collection period and willing to participate. HCPs practicing in TASH but not hired by the hospital (i.e. students) were excluded from the study.

\section{Sample size determination and sampling procedure}

Sample size required for the present study was calculated using the following single population proportion formula.

$$
\mathrm{n}=\frac{Z \alpha / 2^{2} P(1-p)}{d^{2}}
$$

When we take two tailed $Z_{\alpha / 2}$ value of $95 \%$ confidence interval (1.96), 50\% prevalence of ADR reporting knowledge and $5 \%$ of marginal error (d), the sample size was 384 . There were 756 HCPs $(\mathrm{N}=756)$ who fulfilled the inclusion criteria of the study. Since this number is less than 10,000, the sample size has been corrected using the following sample correction formula. The corrected sample size hence was 255 ; including a $10 \%$ non-response rate yielded a final sample size of 280 .

$$
\text { Corrected sample size }=\frac{n \times N}{n+N}
$$

After having the determined sample size, samples for the study were proportionally stratified based on profession. Systematic random sampling technique was used with sampling fraction $(\mathrm{k})$ which was varied for each profession. The sample size was distributed over professions based on their proportion from the total HCPs. Accordingly; questionnaires were administered to 5 physicians, 12 anesthetists, 28 pharmacists and 235 nurses.

\section{Data collection Instrument and interpretation of result}

Data was collected using structured self-administered questionnaire with information on socio-demographic characteristics, knowledge, attitude and practice on ADRs reporting adapted from reviewing different literatures and previous studies ${ }^{11,14-18}$.

The questionnaire includes 7 questions to assess HCPs' knowledge on ADRs reporting. A knowledge score was prepared as a guiding tool to assess knowledge, whereby one point for correct answer and zero for wrong answer. HCPs were categorized based on their overall knowledge scores using original Bloom's cutoff points. The score ranges with their respective knowledge levels were: $80-100 \%, 60-79 \%$ and $<60 \%$ of maximum score as good, moderate and poor knowledge respectively.

There were 9 questions in the attitude part. Respondents were asked to indicate their level of agreement or disagreements on a five point Likert scale containing 'Strongly agree', 'agree', 'neutral', 'disagree' and 'Strongly disagree' on the scale, valued 5 to 1 respectively. The interpretation for negatively worded questions was reversed. The sum of all items will give maximum score of 45 . Seventy five percent of the maximum score i.e. a score of 33.75 was taken as a cutoff point to categorize respondents into two categories, greater than and equal to 33.75 were categorized as having positive attitude and those who scored less than 33.75 were categorized as having negative attitude towards ADR reporting. Five questions were used to assess respondents' practice towards ADRs reporting. The data was entered and analyzed using SPSS version 21.0. It was summarized as frequency and percentage. 


\section{Data quality assurance and quality control}

The questionnaire was pretested on 14 HCPs working at Mizan Tepi University Teaching hospital to check its suitability for the actual data collection. Before starting data collection, brief explanation on how to fill the questionnaire was given for each health professionals. The questionnaire was checked for completeness by principal investigator.

Ethical consideration: Before the actual data collection process, an official cooperation letter was obtained from Mizan-Tepi University, college of health sciences and submitted to clinical director of TASH, then data collection was commenced after permission from the director. Brief explanation on objective of the study was given for HCPs and written consent was secured.

\section{RESULTS}

\section{Background characteristics of participants}

Self-administer questionnaire was distributed to 280 HCPs working at inpatient wards of TASH. Among HCPs initially approached, only 213 HCPs adequately filled and returned the questionnaires, giving a response rate of $76.1 \%$. Hence, $213 \mathrm{HCPs}$ were considered for analysis. Females comprised $54 \%$ of the respondents. Most of the respondents were in the age range of 26-35 years, which accounted for $51.1 \%$. Nurses comprised the major type of HCPs included in the study accounted for $75.6 \%$ of the respondents. Majority, 192(90.1\%) of the respondents were bachelor degree holders. One hundred twenty two $(57.3 \%)$ HCPs were having a clinical experience of 1-5 years (Table 1).

Table 1: Background characteristics of HCPs at inpatient wards of TASH (N=213), March, 2016

\begin{tabular}{lll}
\hline Variables & Category & Frequency (\%) \\
\hline Sex & Female & $115(54.0)$ \\
& Male & $98(46.0)$ \\
Age & $\leq 25$ & $85(39.9)$ \\
& $26-35$ & $109(51.1)$ \\
& $36-45$ & $11(5.2)$ \\
& $>45$ & $8(3.8)$ \\
Profession & Nurse & $161(75.6)$ \\
& Pharmacist & $27(12.7)$ \\
& Anesthetist & $10(4.7)$ \\
Level of education & Midwife & $10(4.7)$ \\
& Physician & $5(2.3)$ \\
& Diploma & $8(3.8)$ \\
Years of clinical experience & Bachelor degree & $192(90.1)$ \\
& MSc or equivalent & $13(6.1)$ \\
\hline
\end{tabular}

Table 2: Knowledge of HCPs at inpatient wards of TASH on ADR Reporting, March, 2016

\begin{tabular}{lc}
\hline Questions & Yes, Number (\%) \\
\hline Differentiate ADR from drug side effect & $114(53.5)$ \\
Know the term pharmacovigilance & $66(31.0)$ \\
Know the existence of national ADR monitoring system & $78(36.6)$ \\
Know the ADR reporting form & $59(27.7)$ \\
ADRs are not well documented at the time the drug is marketed & $140(65.7)$ \\
Where to send ADR report & $29(13.6)$ \\
MOH & $106(49.8)$ \\
FMHACA* & $18(8.4)$ \\
PFSA & $45(21.2)$ \\
EPA & $15(7)$ \\
Do not know & $117(54.9)$ \\
Types of medication candidate for ADR reporting & $106(49.8)$ \\
Conventional medicines & $35(16.4)$ \\
Vaccines and blood products & $64(30.0)$ \\
Traditional medicines & $86(40.4)$ \\
Medicated cosmetics & $7(3.3)$ \\
\hline Medical devices & \\
\hline All (7.1. to 7.5)* & \\
\hline
\end{tabular}

*correct knowledge, MOH: Ministry of health, FMHACA: food, medicine, healthcare administrative and control authority, PFSA: pharmaceutical fund and supply agency, EPA: Ethiopian pharmaceutical association 


\section{Knowledge of HCPs on ADRs reporting}

Upon analysis of questions that were used to assess knowledge, the result revealed that 21(9.8\%), 24(11.3\%) and $168(78.9 \%)$ HCPs have good, moderate and poor knowledge on ADR reporting, respectively. Among the respondents, $106(49.8 \%)$ knew the responsible body to whom ADR should be reported (Table 2). As per Ethiopian context, FMHACA is a regulatory body responsible for receiving and monitoring ADR reports.

\section{Attitude of the HCPs towards ADR reporting}

The present study found that $186(87.3 \%)$ HCPs agreed on regular reporting of ADR, and 179(84\%) HCPs agreed on ADR reporting as part of duty of health professionals. In addition, 192(90.1\%) agreed on its importance for the patient and $117(54.9 \%)$ agreed on reporting ADR should be mandatory (Table 3). Overall, $52.1 \%$ of HCPs had positive attitude towards ADR reporting.

Table 3: Attitude of HCPs at inpatient wards of TASH on ADR Reporting, March, 2016

\begin{tabular}{llllll}
\hline Statements & SA & Agree & Neutral & disagree & SDA \\
\hline ADR should be reported regularly & $118(55.4)$ & $68(31.9)$ & $5(2.3)$ & $10(4.7)$ & $12(5.6)$ \\
ADR reporting is part of duty of health professionals & $107(50.2)$ & $72(33.8)$ & $12(5.6)$ & $11(5.2)$ & $10(4.7)$ \\
ADR reporting is important for the patient & $140(65.7)$ & $52(24.4)$ & $11(5.2)$ & $10(4.7)$ & $0(0)$ \\
ADR reporting is important for the public & $103(48.4)$ & $79(37.1)$ & $18(8.4)$ & $4(1.9 \%)$ & $9(4.2 \%)$ \\
ADR reporting is important for the health care system & $131(61.5)$ & $66(31)$ & $11(5.2)$ & $2(0.9 \%)$ & $2(0.9)$ \\
$\begin{array}{l}\text { There is a need to be sure that ADR is related to the } \\
\text { drug before reporting }\end{array}$ & $98(46.0)$ & $66(31.0)$ & $29(13.6)$ & $18(8.4)$ & $2(0.9)$ \\
$\begin{array}{l}\text { Only ADRs of prescription drugs need to be reported } \\
\text { Only ADRs that cause persistent disability or }\end{array}$ & $36(16.9)$ & $58(27.2)$ & $31(14.6)$ & $67(31.4)$ & $18(8.4)$ \\
$\begin{array}{l}\text { incapability should be reported } \\
\text { Reporting of ADR should be voluntary }\end{array}$ & $32(15)$ & $43(20.2)$ & $18(8.4)$ & $62(29.1 \%)$ & $58(27.2)$ \\
\hline
\end{tabular}

SA: strongly agree, SDA: strongly disagree

\section{Practice of the HCPs towards ADR reporting}

This study revealed that $82(38.5 \%)$ HCPs encountered at least one patient with ADR during their clinical practice in the last one year. Seventy four $(90.2 \%)$ HCPs reported the ADR they encountered, of which only $8(10.8 \%)$ reported to the appropriate body, FMHACA. Among the respondents $82(38.5 \%)$ HCPs claimed they usually give advice to their patients on possible ADRs of drugs (Table 4).

Table 4: ADR reporting practice of HCPs at inpatient wards of TASH, March, 2016

\begin{tabular}{|cc}
\hline Variables & Yes, Frequency (\%) \\
\hline Encountered patient with ADR during the last 12 months & $82(38.5 \%)$ \\
\hline Number of patients encountered with ADR (N=82) & $30(36.6)$ \\
One & $30(36.6)$ \\
Two & $8(9.8)$ \\
Three & $9(11.0)$ \\
\hline Four & $5(6.0)$ \\
\hline$\geq$ Five & $82(38.5 \%)$ \\
Usually give advice to patients on possible adverse effects of the drugs & $74(90.2 \%)$ \\
Reported the ADRs encountered & $28(37.8)$ \\
To whom ADR reported (N=74) & $6(8.1)$ \\
\hline Head of the pharmacy & $16(21.6)$ \\
\hline Manufacturers & $10(13.5)$ \\
\hline MOH & $8(10.8)$ \\
\hline Physician & $3(4.1)$ \\
\hline FMHACA & $3(4.1)$ \\
\hline Head nurse & $82(38.5)$ \\
\hline Other* & $61(28.6)$ \\
\hline Advice patients about possible adverse effects of drugs & $53(24.9)$ \\
\hline Usually & $17(8)$ \\
\hline Sometimes & \\
\hline Rarely & \\
\hline Never &
\end{tabular}




\section{DISCUSSION}

Adverse drug reactions result in an excessive healthcare costs through increased morbidity, mortality and hospital admissions. Therefore, monitoring of ADRs is an integral component of patient care. The study was conducted among 213 HCPs working at TASH inpatient wards to assess their knowledge and attitude towards ADR reporting as well as to evaluate the practice of encountered ADR reporting. The study included physicians, pharmacists, nurses, midwives and anaesthetists.

In the current study, out of $213 \mathrm{HCPs}$, only $53.5 \%$ said that ADR is different from side effect, but only $31 \%$ reported that they knew the term pharmacovigilance. As per WHO recommendation, the term side effect should be reserved for minor effects of drug which are related with its pharmacological properties ${ }^{19}$. There is a need to work to upgrade knowledge of professionals on different form of unintended effects of drugs. This helps for professionals to differential things to be reported from minor side effects.

Among the respondents, $63.4 \%$ knew the presence of national ADR reporting system, which is greater than $45.2 \%^{16}, 37.4 \%^{20}, 23.2 \%^{18}$ reported by previous studies conducted in other health facilities in Ethiopia. This might be the difference in access to information about the presence of ADR reporting centre. Health professionals in TASH could have better information access than those working in peripheral part of the country, with better media outlet in the capital, Addis Ababa. Despite slightly higher knowledge about physical presence of ADR reporting centre as compared with reported from other part of the country, only $27.7 \%$ of HCPs knew the ADR reporting form. This result is almost consistent with $25.6 \%$ reported by Angamo et al ${ }^{18}$, but higher as compared to $20.6 \%$ reported from Jimma zone hospitals in Ethiopia ${ }^{20}$. However, this finding was lower than the result found in Uganda, $37.7 \%^{15}$ and Ethiopia, $48.7 \%{ }^{16}$. The regulatory body should enhance the distribution of prepaid report form to different wards of TASH.

This study found out that $87.3 \%$ of HCPs agreed the fact that ADR should be reported spontaneously at regular basis, which is in line with the findings from similar study in Addis Ababa, $88.9 \%{ }^{21}$. The present study showed that $84 \%$ of healthcare professionals believed ADR reporting as part of duty of health professionals,

\section{REFERENCES}

1. World Health Organization. Policy perspectives on medicines Pharmacovigilance: ensuring the safe use of medicines. WHO, Geneva, Switzerland. 2004

2. Kharkar M, Bowalekar S. Knowledge, attitude and perception/ practices (KAP) of medical practitioners in India towards adverse drug reaction (ADR) reporting. Perspect Clin Res. 2012; 3(3):90-4.

3. Food, Medicine, Healthcare administration and control authority of Ethiopia. Guideline for Adverse Drug Events Monitoring ( Pharmacovigilance ). FMHACA, Addis Ababa Ethiopia, 2014.

4. Agarwa R, Daher AM, Ismail NM. Knowledge, Practices and Attitudes Towards Adverse Drug Reaction Reporting by which is relatively comparable with the $78.3 \%$ obtained from Nekemte, Ethiopia ${ }^{16}$, but lower than the results reported from Addis Ababa, 96.6\% ${ }^{22}$ and $92.7 \%{ }^{21}$. The result of this study revealed that $90.1 \%, 85.5 \%$ and 92.5\% of HCPs believed that ADR reporting is important for the patient, public and healthcare system respectively. One hundred six four HCPs (77\%) claimed that there is the need to be sure that ADR is related with the drug before reporting. The study conducted in Jimma and Addis Ababa revealed that $85.4 \%$ and $76.9 \%$ of study respondents, respectively, believed the need to be sure that ADR is attributed to the suspected drug ${ }^{18,21}$

This study revealed that $38 \%$ in contrast with $81 \%$ in Northern Nigeria ${ }^{14}$ and $11.3 \%$ in Nekemte hospital ${ }^{16}$ of the respondents encountered at least one patient with ADR during their clinical practice in the last one year. Among those HCPs who encountered ADRs, 90.2\% claimed that they have reported the ADR, despite only $10.8 \%$ reported to appropriate body, FMHACA. This showed that most of the healthcare professionals who recognized ADR did not report to the concerned body. This might be due unavailability of reporting form in wards and lack of awareness of the existence of reporting centre.

Limitations of the present study includes possibility of recall bias and the result of the study does not claim to represent all healthcare professionals in TASH, as the respondents were recruited only from inpatient wards.

\section{CONCLUSIONS AND RECOMMENDATIONS}

The present study identified that healthcare professionals working in the TASH, Addis Ababa, Ethiopia had poor knowledge, attitude and practice towards ADRs reporting. This study strongly suggests TASH inpatient ward coordinators to facilitate training programs regarding the importance of ADR reporting to improve knowledge, attitude and practice of healthcare professionals.

Conflict of interest: The authors of this paper declared that there is no competing conflict of interest.

Authors' contribution: All authors conceived design of the study and involved in data acquisition, analysis and interpretation. AT draft the manuscript while TT revise for its intellectual contents. All authors read and approved the manuscript.
Private Practitioners from Klang Valley in Malaysia. Malasys J Med Sci. 2013; 20(2):52-61.

5. Jordan Food and Drug administration. Guidelines for Detecting \& Reporting Adverse Drug Reactions: Individual Case Safety Reports For Healthcare professionals. JFDA. 2014

6. Drug administration and control authority. Report on the assessment of healthcare providers knowledge, attitude and practice on Advers drug reaction reporting and its monitoring. Addis Ababa, Ethiopia. 2008.

7. Boeker EB, de Boer M, Kiewiet JJS, Lie-a-huen L, Dijkgraaf MGW, Boermeester MA. Occurrence and preventability of adverse drug events in surgical patients: a systematic review of literature. BMC Health Serv Res. 2013; 13(1):364 
8. Sharma A, Kellarai A. Pharmacovigilance and adverse drug reaction reporting perspectives among interns and postgraduates of a teaching hospital. J Pharmacol Pharmacother. 2014; 5(4):248-50.

9. Eland IA, Belton KJ, Grootheest ACV, Meiners AP, Rawlins MD, Stricker BHC. Attitudinal survey of voluntary reporting of adverse drug reactions. Br J Clin Pharmacol. 1999; 48(1):623-7.

10. Bäckström M, Ekman E, Mjörndal T. Adverse drug reaction reporting by nurses in Sweden. Eur J Clin Phamacology. 2007; 63:613-8

11. Mulatu WN, Worku A. Pharmacovigilance Assessment of Knowledge, Attitude and Practice of Health Professionals towards Adverse Drug Reaction Reporting and Factors Associated with Reporting. J Pharmacovigil. 2014; 2(4).

12. Bhagavathula AS, Elnour AA, Jamshed SQ, Shebab A. Health Professionals Knowledge, Attitudes and Practices about Pharmacovigilance in India: A Systematic Review and MetaAnalysis. PLoS One. 2016; 11(3):e0152221.

13. Ermias A, Gurmesa G, Mesfin M, Mengistu A. Adverse Drug Reaction Monitoring in Ethiopia: Analysis of case reports, 2002-2007. Ethiop J Heal Dev. 2011; 25(2):168-73.

14. Fadare JO, Enwere OO, Afolabi AO, Chedi BAZ, Musa A. Knowledge, Attitude and Practice of Adverse Drug Reaction Reporting among Healthcare Workers in a Tertiary Centre in Northern Nigeria. Trop J Pharm Res. 2011; 10(3):235-42.

15. Katusiime B, Semakula D, Lubinga SJ, Katusiime B. Adverse drug reaction reporting among healthcare workers at Mulago National Referral and Teaching hospital in Uganda. Afr Health
Sci. $2015 ; 15(4): 1308-17$.

16. Tariku B, Mulisa E, Tesema S. Health Professionals' Knowledge, Attitude And Practices Towards Adverse Drug Reaction Reporting In Nekemte Hospital, Ethiopia. MDMedical Data. 2015; 7(1):041-6.

17. Adimasu A. Nurses knowledge related to adverse drug reaction reporting and associated factors at Felegehiwot Referral Hospital and University of Gondar Teaching Hospital , Northwest Ethiopia. Am J Heal Res. 2014; 2(4):164-70.

18. Angamo MT, Tesfa A, Wabe NT. Knowledge, Attitude and Practice of Adverse Drug Reaction Reporting among Health Professionals in Southwest Ethiopia. TAF Prev Med Bull. 2012; 11(4):397-406

19. World Health Organization. The importance of Pharmacovigilance: safety monitroring of medicinal products. WHO. 2002.

20. Teshale C, Melaku R. Knowledge, attitude and practice of Health professionals towards Adverse drug reaction reporting in Jimma Zone hospitals, Southwest Ethiopia. Pharmacologyonline. 2010; 2:308-15.

21. Alem Denekew. Knowledge, attitude and practice of adverse drug reaction reporting and affecting factors among healthcare providers working in ART clinics of public health facilities in Addis Ababa. Addis Ababa University, masters thesis, 2014.

22. Ayalnesh Goshime. Assessment of Knowledge, Attitude and Practices on Adverse Drug Reaction Reporting among Pharmacy Personnel Working at Community Pharmacy, Addis Ababa, Ethiopia. Addis Ababa University. masters thesis. 2015 . 